\title{
COMUNICAÇÃOO
}

\section{TENTATIVAS DE USO DE RAIOS GAMA PARA PREVENIR INFECÇÃO TRANSFUSIONAL PELO TRYPANOSOMA CRUZI}

\author{
Vicente Amato Neto, Jacyr Pasternak, Luís Matsubara, Nelson \\ Hammerschlak e Fábio Luís Carignani.
}

Transfusão de sangue é expressiva modalidade alternativa de transmissão da infecção devido ao Trypanosoma cruzí. No conjunto das maneiras diferentes da atribuída à participação de triatomíneos, participa ao lado das veiculações congênitas, pelo leite, acidental em laboratório, por órgão transplantado e pela via oral. Exige prevenção correta e sistemática, atualmente, baseada sobretudo na seleção de doadores, através da execução de provas sorológicas. Todavia, a despeito da utilidade dessa conduta, é lícito reconhecer que vigoram algumas dificuldades, representadas mormente pela pouca disponibilidade de recursos humanos bem preparados, pelo custo ou insatisfatória comercialização de reagentes confiáveis e pelas escassas estruturas laboratoriais satisfatoriamente implantadas. Vale salientar também que resultados duvidosos e inconclusivos de exames triadores não são raros, em contexto que já mereceria apoio de técnica simples e barata.

Diante do exposto, afigura-se judicioso procurar verificar a eventual efetividade profilática de outros meios, constituídos, por exemplo, pelo uso de agentes físicos e químicos. O emprego da violeta de genciana é eficiente $e$ isso está sobejamente comprovado. Esse corante, quando aplicado de acordo $\mathrm{com}$ as recomendações divulgadas, elimina o perigo de contágio transfusional, agindo de maneira inócua $a^{5}$ Nào obstante, configura tática só acatada em poucos lugares, apesar da nula ou defeituosa seleção sorológica referente a muitos outros.

\footnotetext{
Laboratório de Investigação Médica-Parasitologia do Hospital de Clínicas da Faculdade de Medicina da Universidade de São Paulo e Serviço de Hemoterapia do Hospital Israelita "Albert Einstein"de São Paulo, SP. Endereço para correspondência: Prof. Vicente Amato Neto. Lab Invest Médica-Parasitol/HC/FM/USP. Av. Dr. Enéas de Carvalho Aguiar 500, 05403-000 São Paulo, SP.

Recebido para publicação: 05/06/95.
}

Com o intuito de efetuar especulações nesse campo, levamos a cabo algumas observações recorrendo a modelo experimental, praticado em alguns camundongos, e imitande o que se faz habitualmente quando de sangue tem lugar.

Considerando que raios gama eliminam a infectividade do T. cruzi presente em sangue, decidimos utilizá-los isoladamente ou em associação com fármacos que promovem radiossensibilização ou agem inativando o parasita, sendo eles o derivado da artemisinina denominado artemeter, a anfotericina $\mathrm{B}$ lipossomal, o itraconazole e o metronidazole ${ }^{237}$. Incluímos o artemeter, antipalúdico, apenas especulativamente.

Os efeitos de diferentes doses, de até 90krda, de radiação gama sobre morfologia, motilidade, reprodutibilidade, virulência e capacidade protetora de formas de cultura do $T$. cruzi, mantidas em meio adequado ou inoculadas em camundongos, encontram-se descritos. As verificações variaram de acordo com os quesitos analisados, em estudo sem nexo com hemoterapia ${ }^{6}$.

Organizamos vários grupos com dez camundongos cada, em correspondência com as múltiplas avaliações realizadas. Os animais de linhagem isogênica (Balb-C), fêmeas, com cerca de $20 \mathrm{~g}$ de peso, provieram do Biotério da Faculdade de Medicina da Universidade de São Paulo.

Os diversos experimentos encontram-se a seguir especificados: a) controle da infecção pelo $T$. cruzi; b) raios gama (2500rda); c) raios gama (5000rad); d) anfotericina B lipossomal $(5 \mathrm{mg})$; e) anfotericina B lipossonal (5mg) e raios gama (2500rad); f) anfotericina B lipossomal $(5 \mathrm{mg})$ e raios gama (5000rad); g) artemeter $(80 \mathrm{mg})$; h) artemerter $(160 \mathrm{mg})$; i) artemeter (80mg) e raios gama(5000rad); j) artemeter $(160 \mathrm{mg})$ e raios gama $(5000 \mathrm{rad}) ; \mathrm{k})$ itraconazole $(50 \mathrm{mg})$ e raios gama (2500rad); 1) itraconazole (100mg) e raios gama (2500rad); $\mathrm{m}$ ) itraconazole 
Comunicação. Amato Neto V, Pastemak. J, Matsubara L, Hammerschlak N. Carignani FL. Tentativas de uso de raios gama para prevenir infeç̧âo transfusional pelo Trypanosoma cruzi. Revista da Sociedade Brasileira de Medicina Tropical 29:613-614, not-dez, 1996.

(500mg) e raios gama (2500mg); n) metronidazole (500mg); o) metronidazole (500mg) e raios gama (2500rad).

A cada bolsa com sangue para transfusão, dentro do prazo de validade e mantida em geladeira, como tem lugar rotineiramente, introduzimos 100.000 tripomastigotas do $T$. cruzi e, logo após, os fármacos, conforme está detalhado. O conjunto permaneceu entre $4^{\circ}$ a $8^{\circ} \mathrm{C}$ durante 24 horas e, então, houve atuação dos raios gama, no tempo suficiente para obtenção da quantidade de radiação desejada; procedemos à irradiação por meio de fonte de césio 137 ("Gammacell - Atomic Energy of Canada"). Prosseguindo, retiramos $10 \mathrm{ml}$, a fim de inocular $0,2 \mathrm{ml}$, por via intraperitoneal, em cada animal e efetuar hemocultura, além de xenodiagnóstico in vitro. Decorridos dois dias, começamos a examinar o sangue dos camundongos. Já precocemente, detectamos parasitemia em todos e, no vigésimo dia, registramos mortalidade total, tendo sempre sido positivos a cultura e o xenodiagnóstico.

Como informação mais ilustrativa, registramos que 2500 ou 5000 rad sào insuficientes. Pesquisa anterior havia demonstrado a efetividade de 20.000 ou 30.000rad, mas tais doses podem propiciar hemólise e aumento da quantidade de potássio no sangue a ser transfundido?. Infelizmente, os medicamentos juntados não melhoram a performance dos raios gama.

A anfotericina $B$ é eficiente quando adicionados ao sangue $3 \mathrm{mg} / 1$ e havendo permanência por horas, à temperatura de $4^{\circ} \mathrm{C}$. Contudo, jamais foi empregada e hemoterapeutas estimulados não se propuseram a avaliar os méritos dela com a finalidade de coibir a infecçcão tripanossômica transfusional, em atitude que precisaria levar em conta significativo aumento do potássio e diminuição do sódio nos recipientes ${ }^{i}$. Cremos que a lipossomal, na qual depositávamos esperança, fracassou integralmente, porque é necessário que seja captada por macrófagos, advindo concentração nos fagossomos, quando válida em tratamentos, sem gerar importantes efeitos adversos.

O modelo experimental ao qual recorremos parece-nos satisfatório, permitindo conclusões acatáveis e, por isso, merecendo preferência posterior nessa linha de estudos. Talvez tenhamos adotado inóculo intenso, se bem que para oḅter dedução irrefutável, sustentadora de trabalho assistencial, garantia é premissa essencial.

\section{AGRADECIMENTOS}

Para Cláudia Regina de Marchi, Meire Lúcia de Oliveira e Iolanda Lima de Souza pelas colaborações prestadas.

\section{REFERÊNCIAS BIBLIOGRÁFICAS}

1. Barreto OCOP,Amato Neto V, Castilho EA, Moreira AAB, Nonoyama K, Tanaka K, Sawastani E, Pinto PLS, Okumura Y, Campos R. Efeito da anfotericina $B$ sobre a viabilidade eritrocitária. Perspectiva do seu uso na prevenção da doença de Chagas induzida pela transfusão de sangue. Revista Paulista de Medicina 101:212-216, 1983.

2. Cruz FS, Marr JJ, Berens RL. Prevention of transfusion-induced Chagas' disease by amphotericin B.The American Journal of Tropical Medicine and Hygiene 29:761-765, 1980.

3. Lichter AS, Lawrence TS. Recent advances in radiation oncology. The New England Journal of Medicine 332:371-379, 1995.

4. Nussenzweig V, Amato Neto V, Freitas JLP, Nussenzweig RJ, Biancalana A. Moléstia de Chagas em Bancos de Sangue. Revista do Hospital da Clínicas da Faculdade de Medicina da Universidade de São Paulo 10:265-283, 1955.

5. Rezende JM, Zupelli W, Bafutto MG. O problema da transmissão da doença de Chagas por transfusão de sangue. Emprêgo da violeta de genciana como medida profilática. Revista Goiana de Medicina 11:35-47, 1965.

6. Salata E, Wiendl FM, Corrêa FMA, Amato Neto V, Castilho VLP, Pinto PLS, Duarte MIS. Efeitos de raios gama sobre Trypanosoma cruzi. Revista do Instituto de Medicina Tropical de São Paulo 15:66-71, 1973.

7. Takeda GKF, Campos R, Keffer J. Moreira AAB, Amato Neto V, Castilho VLP, Pinto PLS, Duarte MIS. Ação de raios gama sobre formas sanguícolas de Trypanlosoma cruzi. Estudo experimental em camundongos. Revista do Instituto de Medicina Tropical de São Paulo 28:5-18, 1986. 